\title{
Coleus aromaticus leaf extract mediated synthesis of silver nanoparticles and its bactericidal activity
}

\author{
Mahendran Vanaja • Gurusamy Annadurai
}

Received: 17 February 2012/Accepted: 7 April 2012/Published online: 25 April 2012

(C) The Author(s) 2012. This article is published with open access at Springerlink.com

\begin{abstract}
The utilization of various plant resources for the biosynthesis of metallic nanoparticles is called green nanotechnology, and it does not utilize any harmful chemical protocols. The present study reports the plantmediated synthesis of silver nanoparticles using the plant leaf extract of Coleus aromaticus, which acts as a reducing and capping agent. The silver nanoparticles were characterized by ultraviolet visible spectroscopy, X-ray diffraction, scanning electron microscopy, energy-dispersive $\mathrm{X}$-ray spectroscopy, Fourier transform infrared spectroscopy, and the size of the silver nanoparticles is $44 \mathrm{~nm}$. The bactericidal activity of the silver nanoparticles was carried out by disc diffusion method that showed high toxicity against Bacillus subtilis and Klebsiella planticola. Biosynthesis of silver nanoparticles by using plant resources is an eco-friendly, reliable process and suitable for large-scale production. Moreover, it is easy to handle and a rapid process when compared to chemical, physical, and microbe-mediated synthesis process.
\end{abstract}

Keywords Biological synthesis - Silver nanoparticle · Electron microscopy $\cdot$ Coleus aromaticus .

UV-vis spectroscopy

\section{Introduction}

Nanotechnology is likely to prominently manipulate science, economy and day-to-day life in this twenty-first

M. Vanaja · G. Annadurai ( $\square)$

Environmental Nanotechnology Division, Sri Paramakalyani Centre for Environmental Sciences, Manonmaniam Sundaranar University, Alwarkurichi 627412, Tamilnadu, India

e-mail: gannadurai@hotmail.com century (Krumov et al. 2009) and their potential effects are used widespread in both in vivo and in vitro biomedical applications and research (Singh et al. 2008). Nanoparticles are the basic essential elements in the wall of nanotechnology and it exhibits fabulous advanced characteristic features based on their properties such as size, morphology and other size dependent properties (Smith et al. 2006). These unique features of nanoparticles may lead to play a crucial role in biomedicine, energy science, optics and other health care applications (Fayaz et al. 2010). Among nanoparticles, silver nanoparticles have potential applications in the arena of life sciences especially in food chemistry ( $\mathrm{Li}$ et al. 2009), forensic science (Cantu 2008), agriculture (Park et al. 2006) and cosmetics (Kokura et al. 2010).

The physical (Xu et al. 2008) and chemical processes (Wang et al. 2005) are the classical general methods used for the fabrication of nanoparticles, but these methods are not environmentally benign (Dubey et al. 2010) and due to the presence of some toxic metals in the synthesis process that may create some dicey effects in biomedical applications (Bar et al. 2009a). These snags in the nanoparticle synthesis are overcome by microbe-mediated and plant-mediated biological process and this bio-route attracts a considerable interest because of its eco-friendliness and biocompatibility (Krumov et al. 2009). Several works has been reported on biosynthesis of silver nanoparticles by using microorganisms such as bacteria (Shahverdi et al. 2007), either intracellularly (Kalishwaralal et al. 2008a) and extracellularly (Kalishwaralal et al. 2008b) fungus (Basavaraja et al. 2008; Balaji et al. 2009) and algae (Vivek et al. 2011). Recently, plant assisted synthesis of nanoparticles have captured a considerable attractive interest in the arena of modern Nanoscience and technology due to its flexibility and ecofriendly nature. Some of the plant materials such as leaves

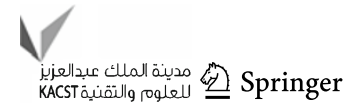


(Satyavani et al. 2011a; Cruz et al. 2010; Elumalai et al. 2010; Huang et al. 2007; Daizy 2011), seeds (Bar et al. 2009b), fruits (Dubey et al. 2010; Jain et al. 2009), latex (Bar et al. 2009a) and barks (Sathishkumar et al. 2009) are involved in the metal reduction process.

Coleus aromaticus Lour. known as Indian Borage belongs to the Lamiaceae family, and it is a commonly available medicinal plant, which is used for the biofabrication of silver nanoparticles. It is a tender, fleshy, highly aromatic pubescent herb with distinctive smelling medicinal plant contains many phytochemicals such as carvacrol (monoterpenoid), caryophyllene (bicyclic sesquiterpene) and patchoulene and flavonoids like quercetin, apigenin, luteolin, salvigenin, and genkwanin (Ram and Mehrotra 1970). It is used for the treatment of malarial fever, hepatopathy, renal and vesical calculi, cough, chronic asthma, hiccough, bronchitis, anthelmintic, colic and convulsions (Nadkarni 1996). In this present study, the leaves of C. aromaticus was used for biosynthesis of silver nanoparticles, biosynthesized silver nanoparticles are characterized by UV-vis spectroscopy, X-ray diffraction (XRD), EDAX, and the capping agent for the silver nanoparticles synthesis was confirmed by Fourier transform infrared spectroscopy (FTIR). Furthermore, the bactericidal effect of silver nanoparticles was also analyzed by disc diffusion method.

\section{Materials and methods}

Plant materials and chemicals

Medicinal plant $C$. aromaticus plant was cultivated at in vivo condition at SPK Centre for Environmental Sciences, Alwarkurichi, Tamilnadu, India. Silver nitrate and all analytical grade chemicals were purchased from Himedia Chemicals Ltd., Mumbai.

\section{Preparation of leaf extract}

About $10 \mathrm{~g}$ of fresh leaves (Fig. 1) was collected and thoroughly washed the leaves with tween 20 and the detergent SDS for 3-4 times. The leaves were chopped into fine pieces and boiled it at $60{ }^{\circ} \mathrm{C}$ for $5 \mathrm{~min}$. The extract was filtered and stored at $4^{\circ} \mathrm{C}$ and then used for nanoparticle synthesis.

Synthesis of silver nanoparticles

The silver nanoparticles were prepared by treating $90 \mathrm{ml}$ of $1 \mathrm{mM}$ silver nitrate with $10 \mathrm{ml}$ of plant extract solution and incubate it at room temperature for $10 \mathrm{~min}$ and observed the brown colour formation, indicating the production of silver nanoparticles (Fig. 2).

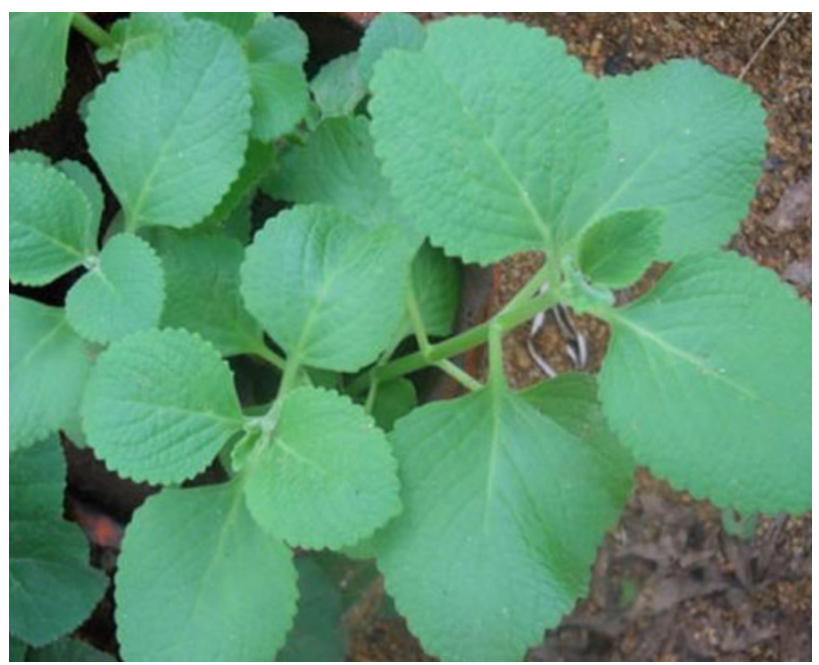

Fig. 1 Picture of Coleus aromaticus leaves

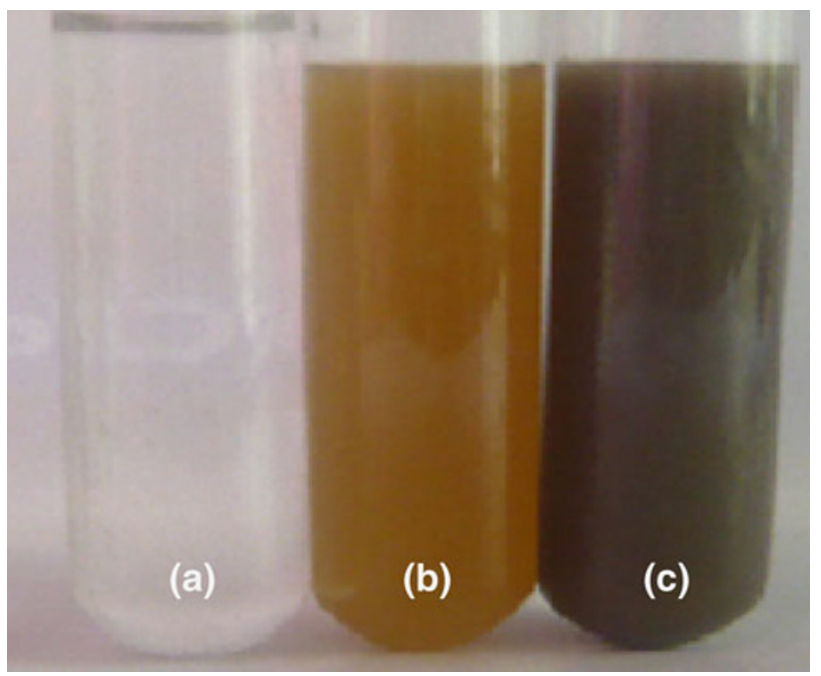

Fig. 2 Formation of silver nanoparticles and it is identification by the colour change. a Silver nitrate solution, b plant extract without silver nitrate, c plant extract with silver nitrate solution

\section{Characterization of silver nanoparticles}

The silver nanoparticle was characterized by UV-spectra at the wavelength ranges from 340 to $740 \mathrm{~nm}$ (Perkin Elmer Lambda double beam UV-Spectrophotometer). The purified silver nanoparticle was obtained by centrifuge the solution at $15,000 \mathrm{rpm}$ for $2-3$ times. The solution was filtered and the pellet was dried in the hot air oven. The dried powder of silver nanoparticles was further analyzed by XRD (Philips PW 1830), EDAX (Philips XL-30). Morphology and size of the silver nanoparticles was characterized by Scanning electron microscopy (SEM) (Philip model CM 200). The FTIR was obtained on a SHIMADZU instrument with the sample as KBR pellet in the wave number region of $500-4,000 \mathrm{~cm}^{-1}$. 
Bactericidal activity of silver nanoparticles

The bactericidal effect of the silver nanoparticle was analysed by disc diffusion method. The two bacterial cultures Bacillus subtilis (3053) and Klebsiella planticola (2277) were purchased from MTCC, India. These two bacterial cultures were grown in Muller Hinton agar (Himedia, Mumbai) petriplates with different concentration of silver nanoparticles containing disc such as 10, 20, 30, 40 and $50 \mu \mathrm{L}$ at $37{ }^{\circ} \mathrm{C}$ for $24 \mathrm{~h}$. After incubation, the antibacterial effect was measured by the formation of zone in the petriplates. The bactericidal activity of biosynthesized silver nanoparticles was also compared with leaf extract and chemically synthesized silver nanoparticles. The standard error was calculated using three replicates of experiments.

\section{Results and discussion}

The formation of nanoparticles was primarily characterized by UV-visible spectroscopy analysis. The formation of dark brown colour clearly indicates the production of silver nanoparticles and it confirmed by the surface plasmon resonance (Shankar et al. 2004) and the formation of dark brown colour because of the oscillation of free electron in the silver nanoparticles (Mulvaney. 1996). Figure 3 shows the UV-visible spectra of silver nanoparticles was measured at different time intervals from 0-24 h. Figure 3 exhibits the UV-vis spectra ranges from 340-740 nm and the strong SPR bands was observed at $460 \mathrm{~nm}$. This SPR band indicates the presence of spherical silver nanoparticles in the solution. The broadening of peaks indicates the nanoparticles are monodispersed. The production of silver nanoparticles was initiated from 2-10 min onwards and vigorously it increases up to $24 \mathrm{~h}$. After $24 \mathrm{~h}$ there was no colour was occurred indicate the completion of the nanoparticles synthesis process. The similar result was reported that silver nanoparticles were formed at $24 \mathrm{~h}$ by using the Lippia citriodora leaf extract (Cruz et al. 2010). Previously, microorganisms such as bacteria and fungi play an important role in the silver nanoparticle synthesis, but some demerits were found in those processes that is the time required for the synthesis of nanoparticle is from 24 to $120 \mathrm{~h}$. In this investigation, using the $C$. aromaticus leaf the silver nanoparticle was synthesized and the nanoparticle formation was initiated at $10 \mathrm{~min}$ and it gets the saturation period is $24 \mathrm{~h}$.

Crystalline size and structure of the silver nanoparticles were carried out by XRD. The biosynthesized silver nanostructure by employing $C$. aromaticus leaf extract was further demonstrated and confirmed by the characteristic peaks observed in the XRD image (Fig. 4). The four distinct diffraction peaks of the $2 \theta$ values of $38.1^{\circ}, 44.1^{\circ}$,

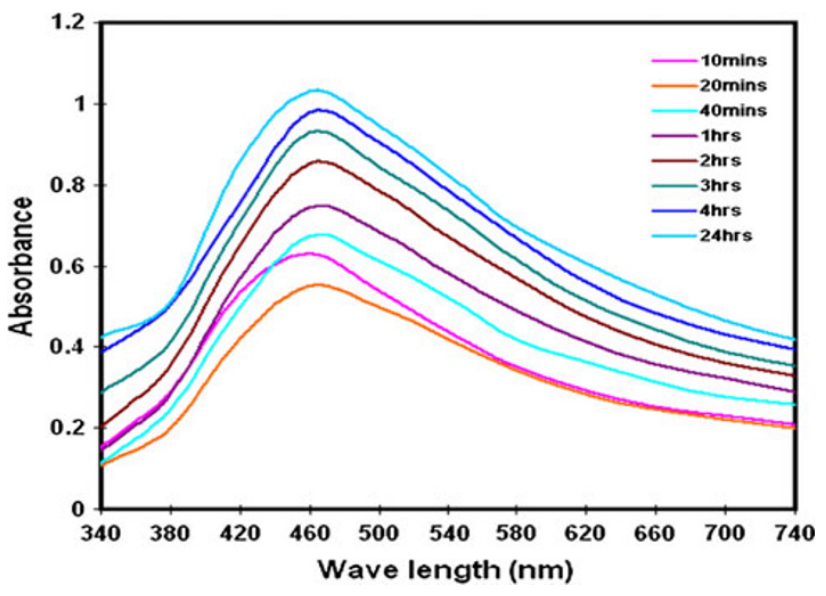

Fig. 3 UV-vis spectra recorded as a function of reaction time of an aqueous solution of $1 \mathrm{mM}$ of $\mathrm{AgNO}_{3}$ with the $10 \mathrm{ml}$ of leaf extract. The reaction time is indicated next to the respective curves

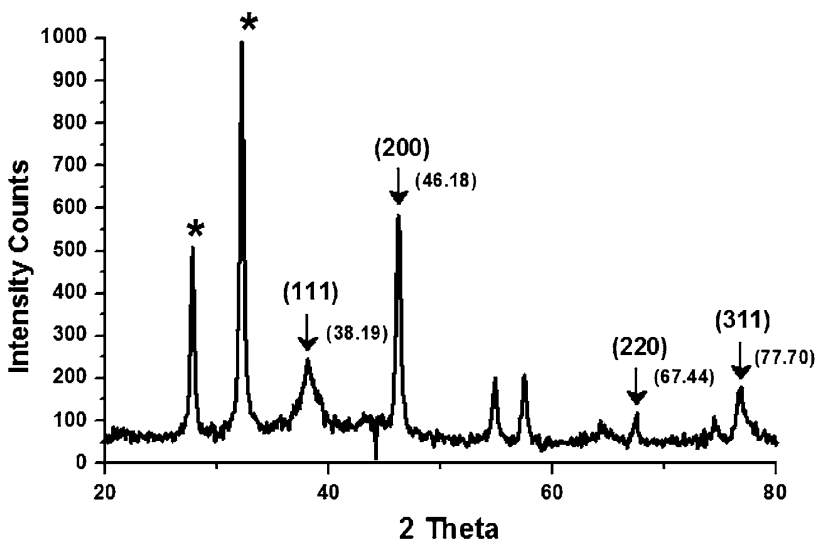

Fig. 4 XRD pattern of silver nanoparticle

$27.8^{\circ}$ and $78.1^{\circ}$ can be assigned the plane of (llll), $\left(\begin{array}{lll}2 & 1 & 0\end{array}\right.$

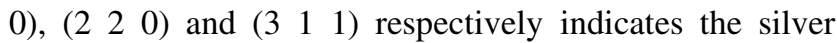
nanoparticles are fcc and crystalline in nature (JCPDS file no. 84-0713 and 04-0783). The broadening of Bragg's peaks indicates the formation of nanoparticles. The mean size of silver nanoparticles was calculated using the Debye-Scherrer's equation

$D=0.94 \lambda / \beta \operatorname{Cos} \theta$

where $D$ is the average crystallite domain size perpendicular to the reflecting planes, $\lambda$ is the $\mathrm{X}$-ray wavelength, $\beta$ is the full width at half maximum (FWHM), and $\theta$ is the diffraction angle. It is found that the calculated average size is $36.1 \mathrm{~nm}$ from FWHM of peaks. A few unassigned peaks (marked with stars) were also observed suggesting that the crystallization of bio-organic phase occurs on the surface of the silver nanoparticles. Similar results in silver nanoparticles synthesized using edible mushroom extract (Daizy. 2009) and also this similar result was reported by using geranium leaves (Shankar et al. 2003). 
The surface morphology and size of the silver nanoparticles was analyzed by Scanning Electron Microscope. SEM image had shown individual silver nanoparticles as well as number of aggregates (Fig. 5). It illustrates the particles are predominantly spherical in shape and aggregates into larger particles with no well-defined morphology. This aggregation may be due to the presence of secondary metabolites in the leaf extracts. The SEM image shows the size of the silver nanoparticles ranging from $40-50 \mathrm{~nm}$. Similar result of the silver nanoparticles size was reported by using Aloe vera extract (Chandran et al. 2006) and by using Euphorbia hirta leaves (Elumalai et al. 2010).

An EDAX study was used to confirm the formation of silver nanoparticles. The EDAX (Fig. 6) recorded from silver nanoparticles showed strong signal of silver from $3 \mathrm{keV}$ with weak signals from $\mathrm{O}$. Weak signals of $\mathrm{O}$ due to $\mathrm{X}$-ray emission from carbohydrates/proteins/enzymes present with in the leaves of $C$. aromaticus. Throughout the scanning range of binding energies, there is no peak to detect the impurity. This result indicated that the product was composed of high purity Ag nanoparticles.

FTIR measurements were carried out to identify the potential functional groups of the biomolecules in the C. aromaticus leaf broth responsible for the reduction of the silver ions. These functional molecules are associated with silver nanoparticles. Figure 7 had shown the FTIR spectra shows that the band at $3,843,2,640 \mathrm{~cm}^{-1}$ corresponds to $\mathrm{NH}$ group of amines. The weak band at $3,337.65 \mathrm{~cm}^{-1}$ shows characteristics of $\mathrm{O}-\mathrm{H}$ stretching of secondary alcohols. The band at $1,636.40 \mathrm{~cm}^{-1}$ corresponds to $\mathrm{C}=\mathrm{O}$ stretching of alcohols (Satyavani et al. 2011a) amide I band and nitro groups. The band at $1,383.65 \mathrm{~cm}^{-1}$ corresponds to $\mathrm{C}-\mathrm{N}$ stretching vibrations of aromatic amines (Satyavani et al. 2011b). The absorbance

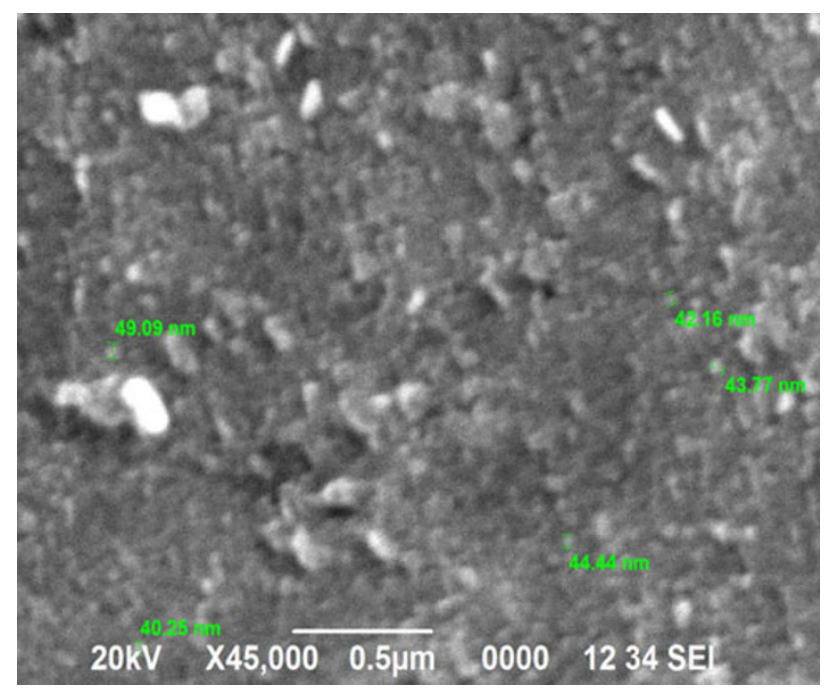

Fig. 5 SEM images of silver nanoparticle

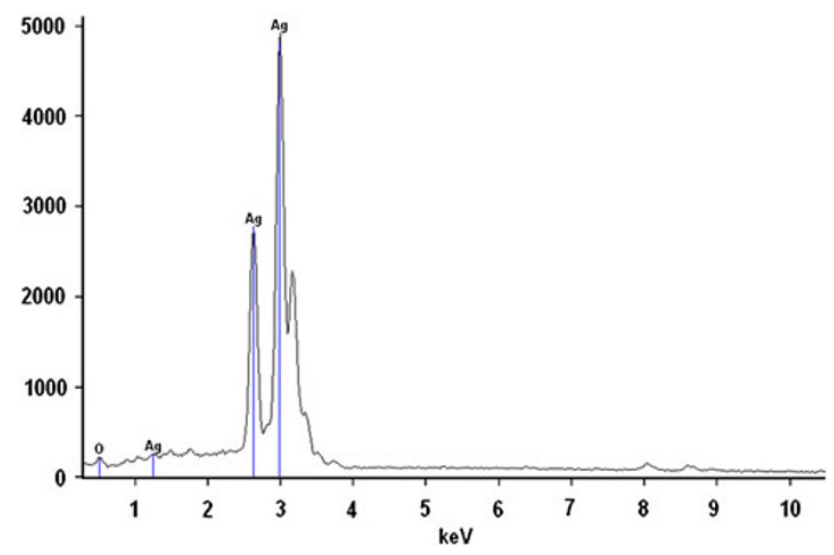

Fig. 6 EDAX pattern of silver nanoparticle

peak at $1,058 \mathrm{~cm}^{-1}$ was disappeared in the capped silver nanoparticles indicates to $\mathrm{C}-\mathrm{N}$ stretching vibrations of aliphatic amines or alcohols or phenols representing the presence of polyphenols may be flavonoids. In this study of FT-IR spectrum confirmed the presence of aromatic amine, amide (I) groups, phenolic groups and secondary alcohols may act as reducing agents for the synthesis of silver nanoparticles.

\section{Bactericidal activity of silver nanoparticles}

The synthesized silver nanoparticle by green route has more highly toxic against $B$. subtilis and $K$. planticola were investigated by disc diffusion method. Table 1 showed a clear inhibition zone whereas the standard antibiotics like chloramphenicol and various concentrations of silver nanoparticles. The concentration of silver nanoparticles was varied from $10-50 \mu \mathrm{L}$. The inhibition of zone increased while increasing the concentration of silver nanoparticles.

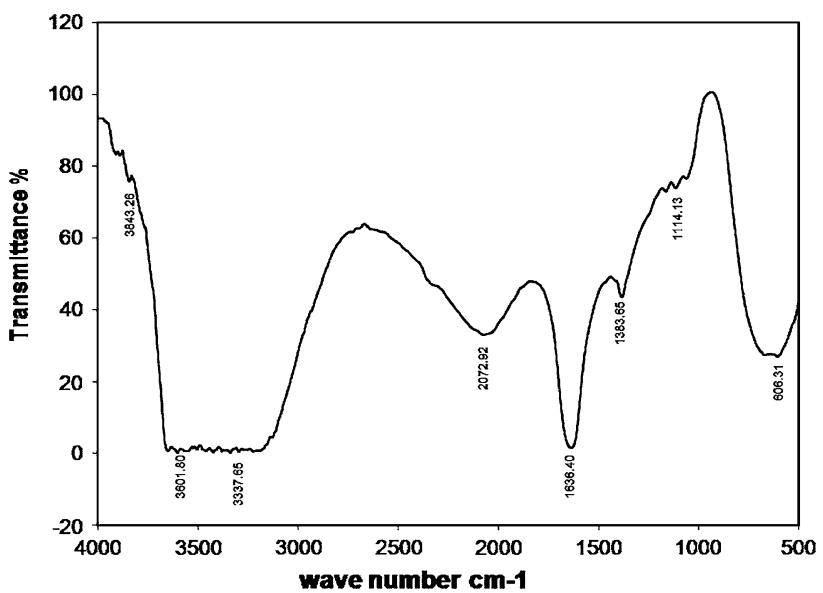

Fig. 7 FT-IR spectrum of leaf extract associated with silver nanoparticles 
Table 1 Shows inhibition zone of silver nanoparticles at various concentration (diameter in $\mathrm{mm}$ )

\begin{tabular}{lcc}
\hline $\begin{array}{l}\text { Concentration of silver } \\
\text { nanoparticles }\end{array}$ & \multicolumn{2}{c}{ Zone of inhibition $(\mathrm{mm}$ in diameter) } \\
\cline { 2 - 3 } & Bacillus subtilis & Klebsiella planticola \\
\hline $10 \mu \mathrm{l}$ & $8.67 \pm 0.33$ & $7.00 \pm 0.578$ \\
$20 \mu \mathrm{l}$ & $10.33 \pm 0.33$ & $8.33 \pm 0.334$ \\
$30 \mu \mathrm{l}$ & $10.33 \pm 1.203$ & $9.00 \pm 0.578$ \\
$40 \mu \mathrm{l}$ & $10.67 \pm 0.668$ & $10.00 \pm 0.335$ \\
$50 \mu \mathrm{l}$ & $12.33 \pm 1.203$ & $11.00 \pm 0.335$ \\
Chloroamphenicol (Control) & $24.67 \pm 0.334$ & $23.33 \pm 0.883$ \\
\hline
\end{tabular}

\pm Standard deviation

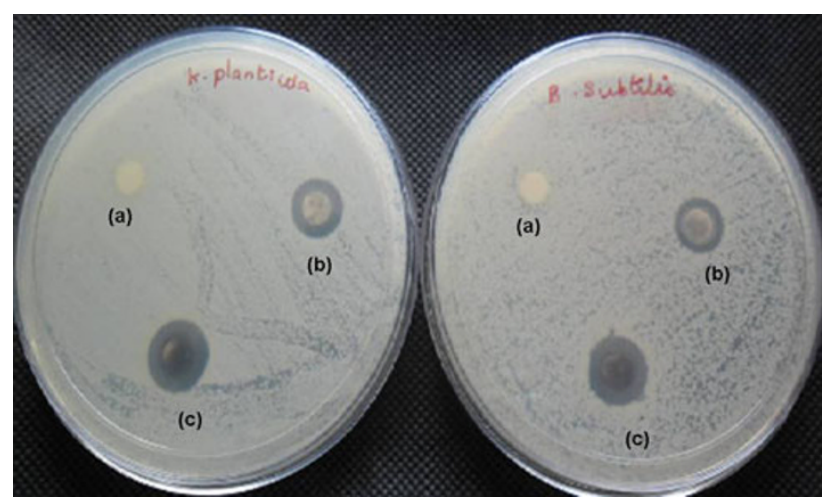

Fig. 8 Comparative study of bactericidal activity of (a) leaf extract of $C$. aromaticus, (b) chemically synthesized silver nanoparticles and (c) biosynthesized silver nanoparticles against Bacillus subtilis and Klebsiella planticola

The zone of inhibition in diameter was tabulated in Table1. Silver nanoparticles inhibit the growth of Gram positive bacteria around the disc of $12.33 \pm 1.203 \mathrm{~mm}$ in diameter in the concentration of $50 \mu \mathrm{L}$. In the Gram negative bacteria the zone inhibition was $11.00 \pm 0.335 \mathrm{~mm}$, observed at $50 \mu \mathrm{L}$ concentration. Our study coincided with the report of Mahitha et al. (2011); they have examined the antibacterial effect of silver nanoparticles against the gram positive (Staphylococcus aureus and B. subtilis) and gram negative bacterium (E.coli and K. pneumonia).

Figure 8 shows high zone inhibition of $C$. aromaticus leaf mediated biosynthesized silver nanoparticles than the leaf extract of $C$. aromaticus and chemically synthesized silver nanoparticles. Biosynthesized silver nanoparticles exhibit more zone inhibition in B. subtilis and $K$. planticola was $14.17 \pm 0.602$ and $12.83 \pm 0.442$, respectively, than leaf extract and chemically synthesized silver nanoparticles (Table 2).

The mechanism of inhibitory action of silver nanoparticles on microorganisms is partially known. Silver nanoparticles are have positive charge, it will attach with the negative charged microorganisms by the electrostatic attraction in the cell wall membrane (Dibrov et al. 2002) and silver nanoparticles are associated with thiol groups of cell wall resulted in the generation of reactive oxygen species and disrupting the cell (Lara et al. 2010). The silver nanoparticles closely associated with cell wall of bacteria by forming 'pits' finally it affects the permeability, and cause cell death (Sondi et al. 2004). The silver nanoparticles were small in size so it easily enters into the bacterial cell and affect the intracellular processes such as DNA, RNA and protein synthesis. Silver nanoparticles were binding with bacteria depends on the surface area for the interaction. Smaller particles affect the larger surface area of the bacteria thus it has more bactericidal activity than the larger sized nanoparticles (Shrivastava et al. 2007).

Previously, scientists used plant materials such as leaves (Satyavani et al. 2011a, b), fruits (Dubey et al. 2010), seeds (Bar et al. 2009b), latex (Bar et al. 2009a) and barks (Sathishkumar et al. 2009) for synthesis of silver nanoparticles. When compare to others plant materials, leaf mediated synthesis gains more advantageous like simple and rapid synthesis of silver nanoparticles (Daizy 2011). Herein, our plant extract synthesized silver nanoparticles within $10 \mathrm{~min}$, and it was confirmed by the colour changes from yellow to brown. The earlier UV-vis spectroscopy reports demonstrated that the silver nanoparticles require $\sim 10$ or more than $10 \mathrm{~min}$ to form in the reaction mixture (Krishnaraj et al. 2010). Whereas, the silver nanoparticles could be synthesized 2-10 min by the $C$. aromaticus leaf extract. The oxidation/reduction property of flavonoids (apigenin, quercetin, myricetin, isorhamnetin and kaempferol) (Rasineni et al. 2008) present in the leaf extract might play an important role in the synthesis of silver nanoparticles. These flavonoids may act as both reducing and stabilizing agents in the synthesis process. The synthesis of silver nanoparticles using $C$. aromaticus is facile and fine compatible method for large-scale production.
Table 2 Shows comparative of bactericidal activity

\pm Standard deviation

\begin{tabular}{lcc}
\hline Concentration of silver nanoparticles & \multicolumn{2}{l}{ Zone of inhibition (mm in diameter) } \\
\cline { 2 - 3 } & Bacillus subtilis & Klebsiella planticola \\
\hline Biosynthesized silver nanoparticles & $14.17 \pm 0.602$ & $12.83 \pm 0.442$ \\
Chemically synthesized silver nanoparticles & $11.67 \pm 0.334$ & $10.67 \pm 0.334$ \\
Pure C. aromaticus leaf extract & $6.17 \pm 0.167$ & $6.5 \pm 0.289$ \\
\hline
\end{tabular}




\section{Conclusion}

The eco-friendly green mediated synthesis of silver nanoparticles using $C$. aromaticus leaf extract was attained with successfully and very rapidly. Silver nanoparticles formation was achieved with in $10 \mathrm{~min}$, which was demonstrated by UV-vis spectroscopy in the absorbance peak at $460 \mathrm{~nm}$. The synthesized nanoparticles were confirmed by XRD and also average size of the nanoparticles was $36.1 \mathrm{~nm}$ calculated by Debye-Scherrer's equation. The EDAX results showed the significant presence of silver. The silver nanoparticles size was in the range of 40-50 nm established by SEM. Capping agent/stabilizing agent play the major role in the reduction of silver ion, which was characterized by FTIR. Green synthesized silver nanoparticles had the bactericidal activity against $B$. subtilis and $K$. planticola was successfully demonstrated by disc diffusion method with zone inhibition on the agar plate. Therefore, this green chemistry approach toward the synthesis of silver nanoparticles has many advantages such as, ease with which the process can be scaled up, economic viability, etc. Applications of such eco-friendly nanoparticles in bactericidal, wound healing and other medical and electronic applications, makes this method potentially exciting for the largescale synthesis of other inorganic materials.

Acknowledgments Authors gratefully acknowledge the DST-FIST sponsored programme, Department of Science Technology, New Delhi, India for funding the research development (Ref no S/FST/ ESI-101/2010) to carry out this work.

Open Access This article is distributed under the terms of the Creative Commons Attribution License which permits any use, distribution, and reproduction in any medium, provided the original author(s) and the source are credited.

\section{References}

Balaji DS, Basavaraja S, Bedre MD, Prabhakar BK, Venkataraman A (2009) Extracellular biosynthesis of functionalized silver nanoparticles by strains of Cladosporium cladosporioides Fungus. Colloids Surf B Biointerfaces 68(1):88-92. doi:10.1016/j.colsurfb. 2008.09.02268:88-92

Bar H, Bhui DH, Sahoo PG, Sarkar P, De PS, Misra A (2009a) Green synthesis of silver nanoparticles using latex of Jatrapha curcas. Colloids Surf A Physicochem Eng Asp 339:134-139. doi: 10.1016/j.colsurfa.2009.02.008

Bar H, Bhui DK, Sahoo GP, Sarkar P, Pyne S, Misra A (2009b) Green synthesis of silver nanoparticles using seed extract of Jatropha curcas. Colloids Surf A Physicochem Eng Asp 348:212-216. doi:10.1016/j.colsurfa.2009.07.021

Basavaraja S, Balaji SD, Lagashetty A, Rajasab AH, Venkataraman A (2008) Extracellular biosynthesis of silver nanoparticles using the fungus Fusarium semitectum. Mater Res Bull 43:1164-1170. doi:10.1016/j.materresbull.2007.06.020

Cantu Antonio A (2008) Nanoparticles in forensic science. Proc of SPIE 7119:71190F doi:10.1117/12.800784
Chandran PS, Chaudhary M, Pasricha R, Ahmad A, Sastry M (2006) Synthesis of gold nanotriangles and silver nanoparticles using Aloe vera plant extract. Biotechnology Prog 22:577-583

Cruz D, Fale LP, Mourato AD, Vaz P, Serralheiro ML, Lino AR (2010) Preparation and physicochemical characterization of $\mathrm{Ag}$ nanoparticles biosynthesized by Lippia citriodora (Lemon Verbena). Colloids Surf B Biointerfaces 81:67-73. doi:10.1016/ j.colsurfb.2010.06.025

Daizy P (2009) Biosynthesis of $\mathrm{Au}, \mathrm{Ag}$ and $\mathrm{Au}-\mathrm{Ag}$ nanoparticles using edible mushroom extract. Spectrochimica Acta Part A 7:374-381. doi:10.1016/j.saa.2009.02.037

Daizy P (2011) Mangifera Indica leaf-assisted biosynthesis of welldispersed silver nanoparticles. Spectrochimica Acta Part A 78:327-331. doi:10.1016/j.saa.2010.10.015

Dibrov P, Dzioba J, Gosink KK, Hase CC (2002) Chemiosmotic mechanism of antimicrobial activity of $\mathrm{Ag}(+)$ in Vibrio cholerae. Antimicrob Agents Chemother 46:2668-2670. doi:10.1128/ AAC.46(8),2668-2670.2002

Dubey SP, Lahtinen M, Sillanpaa M (2010) Tansy fruit mediated greener synthesis of silver and gold nanoparticles. Process Biochem 45:1065-1071. doi:10.1016/j.procbio.2010.03.024

Elumalai EK, Prasad TNVKV, Hemachandran J, Viviyan ST (2010) Extracellular synthesis of silver nanoparticles using leaves of Euphorbia hirta and their antibacterial activities. J Pharm Sci Res 9:549-554

Fayaz A, Balaji M, Girilal M, Yadav R, Thangavelu P, Venketesan KR (2010) Biogenic synthesis of silver nanoparticles and their synergistic effect with antibiotics: a study against gram-positive and gram-negative bacteria. Nanomed Nanotechnol Biol Med 6:103-109. doi:10.1016/j.nano.2009.04.006

Huang J, Li Q, Sun D, Lu Y, Su Y, Yang X, Wang H, Wang Y, Shao W, He N, Chen C (2007) Biosynthesis of silver and gold nanoparticles by novel sundried Cinnanonum camphora leaf. Nanotechnology 18:105104. doi:10.1088/0957-4484/18/10/ 105104

Jain D, Daima HK, Kachhwaha S, Kothari SL (2009) Synthesis of plant-mediated silver nanoparticles using papaya fruit extract and evaluation of their anti microbial activities. Dig J Nanomater Biostruct 4:557-563

Kalishwaralal K, Ramkumarpandian S, Deepak V, Mohd B, Sangiliyandi G (2008a) Biosynthesis of silver nanocrystals by Bacillus licheniformis. Colloids Surf B 65:150-153. doi:10.1016/ j.colsurfb.2008.02.018

Kalishwaralal K, Deepak V, Ramkumarpandian S, Nellaiah H, Sangiliyandi G (2008b) Extracellular biosynthesis of silver nanoparticles by the culture supernatant of Bacillus licheniformis. Mater Lett 62:4411-4413. doi:10.1016/j.matlet.2008.06.051

Kokura S, Handa D, Takagi T, Ishikawa T, Naito Y, Yoshikawa T (2010) Silver nanoparticles as a safe preservative for use in cosmetics. Nanomedicine 6(4):570-574. doi:10.1016/j.nano. 2009.12.002

Krishnaraj C, Jagan EG, Rajasekar S, Selvakumar P, Kalaichelvan PT, Mohan N (2010) Synthesis of silver nanoparticles using Acalypha indica leaf extracts and its antibacterial activity against water borne pathogens. Colloids Surf B Biointerfaces 76(1): $50-56$

Krumov N, Perner IN, Oder S, Gotcheva V, Angelov A, Posten C (2009) Production of inorganic nanoparticles by microorganisms. Chem Eng Technol 32(7):1026-1035. doi:10.1016/j.matlet. 2008.06.051

Lara HH, Ayala-Nuaez NV, Ixtepan-Turrent L, Rodriguez-Padilla C (2010) Bactericidal effect of silver nanoparticles against multidrug-resistant bacteria. World J Microbiol Biotechnol 26:615-621. doi::10.1007/s11274-009-0211-3

Li H, Li F, Wang L, Shengv J, Xin Z, Zhao L (2009) Effect of nanopacking on preservation quality of Chinese jujube (Ziziphus 
jujube Mill. Var. inermis (Bunge) Rehd). Food Chem 114:547552. doi:10.1016/j.foodchem.2008.09.085

Mahitha B, Deva Prasad Raju B, Dillip GR, Reddy CM, Mallikarjuna K, Manoj L, Priyanka S, Rao KJ, Sushma NJ (2011) Biosynthesis, characterization and antimicrobial studies of AgNPs extract from Bacopa monniera whole plant. Dig J Nanomater Biostruct 6(1):135-142

Mulvaney P (1996) Surface plasmon spectroscopy of nanosized metal particles. Langmiur 12:788-800. doi:10.1021/la9502711

Nadkarni AK (1996) Indian Materia Medica, vol I, 2nd edn. Popular Prakasan, Mumbai, p 371

Park HJ, Sung HK, Kim HJ, Choi SH (2006) A new composition of nanosized silica-silver for control of various plant diseases. Plant Pathol J 22:295-302

Ram PR, Mehrotra BN (1970) Compendium of Indian medicinal plants, vol 2. CDRI Lucknow and Publication and Information Directorate. New Delhi, pp 79-201

Rasineni GK, Siddavattam D, Reddy AR (2008) Free radical quenching activity and polyphenols in three species of Coleus. J Med Plants Res 2(10):285-291. ISSN 1996-0875

Sathishkumar M, Sneha K, Won SW, Cho CW, Kim S, Yun YS (2009) Cinnamon zeylanicum bark extract and powder mediated green synthesis of nano-crystalline silver particles and its bactericidal activity. Colloids Surf B 73:332-338. doi:10.1016/ j.colsurfb.2009.06.005

Satyavani K, Ramanathan T, Gurudeeban S (2011a) Plant Mediated Synthesis of Biomedical Silver Nanoparticles by Using Leaf Extract of Citrullus colocynthis. Res J Nanosci Nanotechnol 1:95-101. doi:10.3923/rjnn.2011.95.101

Satyavani K, Ramanathan T, Gurudeeban S (2011b) Green synthesis of silver nanoparticles by using stem derived callus extract of bitter apple (Citrullus colocynthis). Dig J Nanomater Biostruct 6:1019-1024

Shahverdi AR, Fakhimi A, Shahverdi HR, Minaian SA (2007) Synthesis and effect of silver nanoparticles on the antibacterial activity of different antibiotics against Staphylococcus aureus and Escherichia coli. Nanomed Nanotechnol Biol Med 3:168-171. doi:10.1016/j.nano.2007.02.001

Shankar SS, Ahmad A, Sastry M (2003) Geranium leaf assisted biosynthesis of silver nanoparticles. Biotechnol Prog 19:16271631. doi:10.1021/bp034070w

Shankar S, Rai A, Ankamwar B, Singh A, Ahmad A, Sastry M (2004) Biological Synthesis of Triangular Gold Nanoprisms. Nat Mater 3:482-488. doi:10.1038/nmat1152

Shrivastava S, Tanmay BE, Roy A, Singh G, Rao PR, Dash D (2007) Characterization of enhanced antibacterial affects of novel silver nanoparticles. Nanotechnology 18:1-9. doi:10.1088/0957-4484/ $18 / 22 / 225103$

Singh M, Singh S, Prasada S, Gambhir IS (2008) Nanotechnology in medicine and antibacterial effect of silver nanoparticles. Digest Journal of Nanomaterials and Biostructures. 3:115-122

Smith AM, Duan H, Rhyner MN, Ruan G, Nie S (2006) A systematic examination of surface coatings on the optical and chemical properties of semiconductor quantum dots. Physical Chemistry Chemical Physics. 33:3895-3903. doi:10.1039/B606572B

Sondi I, Salopek-Sondi B (2004) Silver nanoparticles as antimicrobial agent: a case study on E. coli as a model for Gram-negative bacteria. J Colloid Interface Sci 275:177-182. doi:10.1016/j.jcis. 2004.02.012

Vivek M, Senthil Kumar P, Steffi S, Sudha S (2011) Biogenic silver nanoparticles by Gelidiella acerosa extract and their antifungal effects. Avicenna J Med Biotech 3(3):143-148

Wang H, Qiao X, Chen J, Ding S (2005) Preparation of silver nanoparticles by chemical reduction method Surf. Colloid A 256:111-115. doi:10.1016/j.colsurfa.2004.12.058

Xu GN, Qiao XL, Qiu XL (2008) Preparation and characterization of stable monodisperse silver nanoparticles via photoreduction. Colloid Surf A 320:222-226. doi:10.1016/j.colsurfa.2008.01.056 